\title{
Comparative pharmacokinetics and tissue distribution of primaquine enantiomers in mice
}

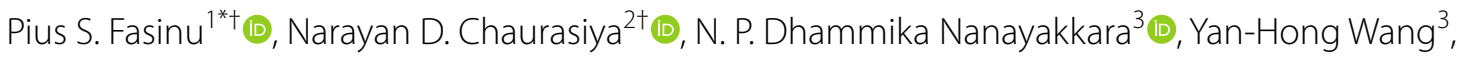 \\ H. M. T. Bandara Herath ${ }^{3}$, Bharathi Avula ${ }^{3}$, James D. McChesney ${ }^{4}$, David Jollow ${ }^{5}$, Larry A. Walker ${ }^{3^{*}}$ (D) and \\ Babu L. Tekwani2*
}

\begin{abstract}
Background: Primaquine $(\mathrm{PQ})$ has been used for the radical cure of relapsing Plasmodium vivax malaria for more than 60 years. $P Q$ is also recommended for prophylaxis and prevention of transmission of Plasmodium falciparum. However, clinical utility of PQ has been limited due to toxicity in individuals with genetic deficiencies in glucose 6-phosphate dehydrogenase (G6PD). PQ is currently approved for clinical use as a racemic mixture. Recent studies in animals as well as humans have established differential pharmacological and toxicological properties of the two enantiomers of PQ. This has been attributed to differential metabolism and pharmacokinetics of individual PQ enantiomers. The aim of the current study is to evaluate the comparative pharmacokinetics (PK), tissue distribution and metabolic profiles of the individual enantiomers in mice.

Methods: Two groups of 21 male Albino ND4 Swiss mice were dosed orally with $45 \mathrm{mg} / \mathrm{kg}$ of S-(+)-PQ and R-(-) $\mathrm{PQ}$ respectively. Each of the enantiomers was comprised of a 50:50 mixture of ${ }^{12} \mathrm{C}$ - and ${ }^{13} \mathrm{C}$ - stable isotope labelled species (at 6 carbons on the benzene ring of the quinoline core). Three mice were euthanized from each group at different time points (at 0, 0.5, 1, 2, 4, 8, 24 h) and blood was collected by terminal cardiac bleed. Liver, spleen, lungs, kidneys and brain were removed, extracted and analysed using UPLC/MS. The metabolites were profiled by tandem mass (MS/MS) fragmentation profile and fragments with ${ }^{12} \mathrm{C}-{ }^{13} \mathrm{C}$ twin peaks. Non-compartmental analysis was performed using the Phoenix WinNonLin PK software module.
\end{abstract}

Results: The plasma $A \cup C_{0-\text { last }}(\mu \mathrm{g} \mathrm{h} / \mathrm{mL})$ (1.6 vs. 0.6), $T_{1 / 2}$ (h) (1.9 vs. 0.45), and $T_{\max }$ (h) (1 vs. 0.5) were greater for SPQ as compared to RPQ. Generally, the concentration of SPQ was higher in all tissues. At $T_{\text {max }}(0.5-1 \mathrm{~h}$ in all tissues), the level of SPQ was 3 times that of RPQ in the liver. Measured $C_{\max }$ of SPQ and RPQ in the liver were about 100 and 40 times the $C_{\max }$ values in plasma, respectively. Similar observations were recorded in other tissues where the concentration of SPQ was higher compared to RPQ $(2 \times$ in the spleen, $6 x$ in the kidneys, and $49 x$ in the lungs) than in the plasma.

\footnotetext{
*Correspondence: pfasinu@uab.edu; Iwalker@olemiss.edu;

btekwani@southernresearch.org

${ }^{\dagger}$ Pius S. Fasinu and Narayan D. Chaurasiya equally contributed to this

study

1 Department of Pharmacology \& Toxicology, University of Alabama

at Birmingham, Birmingham, AL 35294, USA

${ }^{2}$ Department of Infectious Diseases, Division of Scientific Platforms,

Southern Research, Birmingham, AL 35205, USA

${ }^{3}$ National Center for Natural Products Research, Research Institute

of Pharmaceutical Sciences, School of Pharmacy, The University

of Mississippi, University, MS 38677, USA

Full list of author information is available at the end of the article
}

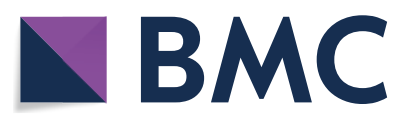

(c) The Author(s) 2022. Open Access This article is licensed under a Creative Commons Attribution 4.0 International License, which permits use, sharing, adaptation, distribution and reproduction in any medium or format, as long as you give appropriate credit to the original author(s) and the source, provide a link to the Creative Commons licence, and indicate if changes were made. The images or other third party material in this article are included in the article's Creative Commons licence, unless indicated otherwise in a credit line to the material. If material is not included in the article's Creative Commons licence and your intended use is not permitted by statutory regulation or exceeds the permitted use, you will need to obtain permission directly from the copyright holder. To view a copy of this licence, visit http://creativecommons.org/licenses/by/4.0/. The Creative Commons Public Domain Dedication waiver (http://creativeco mmons.org/publicdomain/zero/1.0/) applies to the data made available in this article, unless otherwise stated in a credit line to the data. 
$\mathrm{CPQ}$, the major metabolite, was preferentially generated from $\mathrm{RPQ}$, with higher levels in all tissues $(>10 \times$ in the liver, and $3.5 \times$ in the plasma) than from SPQ. The PQ-o-quinone was preferentially formed from the SPQ (>4 $\times$ compared to $\mathrm{RPQ}$ ), with higher concentrations in the liver.

Conclusion: These studies show that in mice, PQ enantiomers are differentially biodistributed and metabolized, which may contribute to differential pharmacologic and toxicity profiles of $\mathrm{PQ}$ enantiomers. The findings on higher levels of PQ-o-quinone in liver and RBCs compared to plasma and preferential generation of this metabolite from $\mathrm{SPQ}$ are consistent with the higher anti-malarial efficacy of SPQ observed in the mouse causal prophylaxis test, and higher haemolytic toxicity in the humanized mouse model of G6PD deficiency. Potential relevance of these findings to clinical use of racemic PQ and other 8-aminoquinolines vis-à-vis need for further clinical evaluation of individual enantiomers are discussed.

\section{Background}

Primaquine (PQ), the prototype 8-aminoquinoline, has been in clinical use as an anti-malarial drug for over six decades. It is primarily prescribed for radical cure of Plasmodium vivax malaria [1,2], which is still a threat in several regions of the world [3-6]. Interest in this broad-spectrum anti-malarial drug has spiked in recent years with the appreciation that it is a prophylactic agent against all forms of malaria that also has activity against the mature and infective gametocytes of Plasmodium falciparum [7-9]. These observations and the recommendations of global health agencies for single-dose PQ use in malaria endemic regions [10-12] raise hope for the utility of PQ in malarial eradication campaigns. However, widespread use of PQ has been limited by the well documented haemolytic toxicity in patients who are genetically deficient in glucose-6-phosphate dehydrogenase (G6PD) activity [13-15]. The recently approved tafenoquine, a long acting 8-aminoquinoline, brought a distinct advantage over PQ in terms of dose regimen (allowing a single dose treatment), but tafenoquine still carries the liability in G6PD deficiency [16-18]. The need for a safer alternative to $\mathrm{PQ}$ has driven efforts to better understand of the mechanisms of PQ efficacy and toxicity with a view to improving its therapeutic index.

Although the precise biomolecular mechanism of the anti-malarial activity of PQ is still not fully understood, recent studies have suggested that cytochrome P450-dependent metabolism is necessary for the generation of both the active and the toxic metabolites [19]. Subsequent reports in animal models and clinical studies indicate a role for CYP2D6 in the efficacy of PQ [20-23]. For example, while PQ completely protected wild-type mice from Plasmodium berghei sporozoite-induced infection, no protection was observed in CYP 2D knockout mice [24]. Similarly, in a clinical study of a vaccine under development, a strong association was established between CYP2D6 activity and the anti-malarial activity of $\mathrm{PQ}$, with the subjects who are CYP2D6 extensive-metabolizers showing no relapse compared to varying relapses in the intermediate- and poor-metabolizer groups [25]. Initial observations have suggested the role of CYP2D6mediated formation of an $o$-quinone metabolite of $\mathrm{PQ}$ [23-27]. It is not as well established, however, whether the CYP2D6-derived metabolite(s) are also responsible for haemolytic toxicity. Thus far, no direct evidence exists that the metabolites produced in the CYP2D6-rich hepatocytes are transported to erythrocytes through plasma.

Currently available formulations of $\mathrm{PQ}$ are a racemic mixture of (-)-(R)-PQ (RPQ) and (+)-(S)-PQ (SPQ) enantiomers in equal proportions. The metabolism of $\mathrm{PQ}$ is enantioselective, as observed in multiple exploratory biotransformation studies [28-32]. Extensive metabolite phenotyping studies have shown that PQ is metabolized via two primary pathways: (a) CYP2D6-dependent pathways of hydroxylation of the quinoline ring; and (b) sequential oxidation of the terminal amine of the side chain by mono-amine oxidase and alcohol dehydrogenase [32, 33]. Direct metabolism of PQ by a phase II conjugation pathway has also been suggested [32]. The $\mathrm{RPQ}$ enantiomer is preferentially metabolized to the deaminated products while the SPQ enantiomer yields more of the CYP2D6-dependent oxidative metabolites. With the now known metabolism-dependent activity of primaquine, it is plausible to expect variation in the efficacy and toxicity of the two PQ enantiomers, as has been suggested by some studies. SPQ has not only shown better causal prophylactic and blood schizonticidal efficacy in $P$. berghei-infected mouse malaria models, but also a stronger propensity to cause haemototoxicity in the non-obese diabetic/severe combined immunodeficiency (NOD/SCID) mouse model engrafted with G6PDdeficient human red blood cells, as well as in beagle dogs [34]. Importantly, in Rhesus monkeys both enantiomers have demonstrated essentially the same radical curative activity against Plasmodium cynomolgi, but the toxicity profiles were divergent $[35,36]$. This suggests that although the metabolic pathways of the enantiomers differ quantitatively, both produce the active/toxic metabolites, albeit to varying degrees. 
It is proposed that a better understanding of differences in the pharmacokinetic and pharmacodynamics properties of individual enantiomers of PQ will provide a better understanding of their differential elimination and of the formation and tissue-distribution of their metabolites. This may, in turn, offer insights into the safer use of PQ and other racemic 8-aminoquinolines.

As an anti-infective agent, the concentration of $P Q$ in the target/infected organs, along with its bioactivation, will be significant determinants of effectiveness. It is noteworthy that in mice, PQ has much better activity against the liver stages of the malaria parasite than against mature blood stages. Differential biodistribution of the PQ enantiomers and metabolites to these sites and organs may offer insights into the safety and efficacy of one enantiomer over the other. Thus, besides the differential formation of the active/toxic metabolites, the biodistribution of PQ and its metabolites are considered important for efficacy and toxicity. Clinical studies in progress in parallel $[37,38]$ will have limited ability to determine relative bio-distribution of individual PQ enantiomers and key metabolites in target organs.

Therefore, the aim of the current study was to conduct a differential pharmacokinetics, metabolism, and tissue biodistribution studies of SPQ and RPQ in uninfected mice.

\section{Methods}

\section{Primaquine dosing and administration}

Preparation of ${ }^{13} \mathrm{C}$-labelled primaquine and primaquine enantiomers

Labelling of drug candidates with stable isotopes have afforded convenient tools for tracking drug-derived metabolites in complex matrices by tandem MS/MS profiling of the metabolites [39]. This allows filtering for masses of drug metabolites and resulting fragments with twin peaks attributable to the label. ${ }^{13} \mathrm{C}$-Primaquine, labeled at 6 benzene carbons of the quinoline ring, was synthesized as earlier reported [40]; individual enantiomers (+)-(S)-PQ (SPQ) and (-)- $(R)-\mathrm{PQ}(\mathrm{RPQ})$ were resolved as previously described [34]. Drugs were prepared as the diphosphate salts. Mixtures $(1: 1)$ of ${ }^{13} \mathrm{C}$ and ${ }^{12} \mathrm{C}$ versions of each enantiomer were prepared as previously described [41]. The mixture was diluted in phosphate buffered saline ( $\mathrm{pH}$ 7.4) for use in in vivo dosing for the tissue distribution studies.

\section{Animals}

All animal procedures were approved by the Institutional Animal Care and Use Committee of the University of Mississippi. The study was carried out on male Albino ND4 Swiss mice (25-30 g). Forty-five male mice weighing 25 to $30 \mathrm{~g}$ were randomly assigned to different groups
(3 mice in each group) for the study. In all studies, animals were maintained in 12-h light 12-h dark cycles, had access to rodent chow and water ad libitum, and housed according to the guidelines of the Institute of Laboratory Animal Research (ILAR) Guide (1996) and the SEQUUS Institutional Animal Care and Use Committee [42]. The animals were observed daily for general well-being throughout the study.

\section{Administration and sampling}

On the day of dosing, 21 mice were orally administered $45 \mathrm{mg} / \mathrm{kg}$ SPQ while another 21 mice received RPQ in saline (doses are expressed as PQ base). The remaining 3 mice received the control saline solution. Doses were based on individual animal's body weight. At each time point (at $0,0.5,1,2,4,8,24 \mathrm{~h}$ ) randomly selected three mice were euthanized by inhalation of isoflurane anesthetic and blood was collected by direct cardiac bleed into heparinized tubes and centrifuged to separate plasma and erythrocytes pellet. Liver, spleen, lungs, kidneys, and brain were removed, washed extensively with chilled saline to remove adherent blood/tissues, and weighed prior to freezing and storage at $-80{ }^{\circ} \mathrm{C}$ until analysis.

\section{Plasma, tissue and urine analysis Sample preparation}

Samples for standard curves were prepared by spiking $200 \mu \mathrm{L}$ of mice plasma with various concentrations of SPQ and RPQ from 100 to $10,000 \mathrm{ng} / \mathrm{mL}$ along with a constant concentration of the internal standard (6-D3-methoxyprimaquine). Tissue samples were homogenized in chilled deionized water using Omni tissue homogenizer. Plasma and homogenized tissue samples were extracted with 2-parts of chilled methanol. The mixtures were vortexed, left on ice for at least $60 \mathrm{~min}$ and centrifuged $(5000 \times g$ for $10 \mathrm{~min})$. The separated supernatants were evaporated to dryness using a SpeedVac. The residues were reconstituted in $200 \mu \mathrm{L}$ methanol, centrifuged and the supernatants were transferred to amber autosampler vials for subsequent injection into the HPLC/MS system. The urinary bladders of three mice from each group were emptied and the collected urine samples were pooled for each group. The urine samples were freeze-dried and reconstituted in methanol as above for HPLC/MS analysis.

\section{UPLC/MS instrumentation and analysis}

A liquid chromatography-mass spectrometry (LC-MS) method for simultaneous analysis of PQ and its metabolites developed previously was employed in this study [40]. The separation of analytes was achieved within a 25-min run time on a Waters ACQUITY UPLC ${ }^{\mathrm{TM}} \mathrm{BEH}$ 
Shield RP18 column $(100 \mathrm{~mm} \times 2.1 \mathrm{~mm}$ I.D., $1.7 \mathrm{~mm})$ equipped with an LC-18 guard column (Vanguard $2.1 \times 5 \mathrm{~mm}$, Waters Corp, Milford, MA, USA) using an ACQUITY UPLC system (Waters Corp, Milford, MA, USA). The UPLC system includes binary solvent manager, sampler manager, column compartment, and photodiode array (PDA) detector. The mobile phase, consisting of water with $0.05 \%$ formic acid (A) and acetonitrile with $0.05 \%$ formic acid (B), was applied at a flow rate of $0.3 \mathrm{~mL} / \mathrm{min}$ in the following gradient elution: $0-5 \mathrm{~min}$, $1 \% \mathrm{~B} ; 5-14 \mathrm{~min}, 1 \% \mathrm{~B}$ to $13 \% \mathrm{~B} ; 14-18 \mathrm{~min}, 13 \%$ B to $25 \%$ B; $18-22 \mathrm{~min}, 25 \%$ B to $33 \%$ B; $22-23 \mathrm{~min}, 33 \%$ B to $43 \%$ $B$, and $23-25 \mathrm{~min}, 43 \%$ B to $100 \%$ B. Each run was followed by a 3-min wash with $100 \% \mathrm{~B}$ and an equilibration period of 3.5 min with $99 \% \mathrm{~A} / 1 \% \mathrm{~B}$. Column and sample temperatures were set at 50 and $15{ }^{\circ} \mathrm{C}$, respectively. Injection volume was $10 \mu \mathrm{L}$, and the strong needle wash (90/10; acetonitrile/water, v/v) and weak needle wash solution (10/90; acetonitrile/water) were used. Peaks were assigned with respect to the mass spectra and retention time of reference compounds or tentatively identified on the basis of high-resolution accurate mass.

Mass spectrometric analyses were performed using electrospray ionization (ESI) in positive mode on a Waters Xevo G2-S QToF mass spectrometer (Waters Corporation, Manchester, UK). The MS instrument was operated in the following conditions: mass scan range of $50-1200 \mathrm{Da}$, capillary of $3.0 \mathrm{kV}$, cone of $30 \mathrm{~V}$, source temperature of $80^{\circ} \mathrm{C}$, desolvation temperature of $450{ }^{\circ} \mathrm{C}$, desolvation gas flow of $800 \mathrm{~L} / \mathrm{h}$, cone gas flow of $50 \mathrm{~L} / \mathrm{h}$, and a collision energy of $6 \mathrm{eV}$. Leucine-enkephalin was used for the lock mass at a concentration of $5 \mathrm{ng} / \mathrm{mL}$ and flow rate of $10 \mu \mathrm{L} / \mathrm{min}$. Ions $[\mathrm{M}+\mathrm{H}]^{+}(\mathrm{m} / z 556.2771 \mathrm{Da})$ and fragment ion $(\mathrm{m} / z 278.1141 \mathrm{Da})$ of leucine-enkephalin were applied to ensure mass accuracy during the MS analysis. The lock spray interval was set at $30 \mathrm{~s}$, and the data were averaged over three scans. The mass spectrometer was programmed to step between low $(10 \mathrm{~V})$ and elevated (10-45 V) collision energies on the gas cell, using a scan time of $0.5 \mathrm{~s}$ per function.

Metabolites in the accurate mass data were phenotyped using the Metabolynx ${ }^{\circledR}$ software. The data were searched using predicted metabolite mass, mass defects, isotope, and fragmentation patterns. Each sample was subjected to data acquisition in full scan and data-dependent positive MS/MS, targeted MS/MS (ESI positive ionization mode) and high-resolution MS (HRMS) modes using the Waters ACQUITYTM XEVO QTOF Mass Spectrometer (Waters Corporation, Manchester, UK) connected to the UPLC system via an electrospray ionization (ESI) interface. UHPLC retention time, twin mass peaks with difference of 6 (originating from (13)C(6)-PQ/ $P Q)$, and MS-MS fragmentation pattern were used for phenotyping the metabolites [40]. Identification of each metabolite was assisted by its HRMS data, which were used to calculate their elemental compositions. The full scan mass data were screened and filtered using Waters MetaboLynx XS software. The qualitative metabolite identification was performed using this software package. Quantitative metabolite analysis of known metabolites (carboxyprimaquine and primaquine $o$-quinone) was performed using standard calibrations.

\section{Pharmacokinetic and statistical analyses}

Three mice were sampled for each time point. The data were analysed using the Phoenix WinNonLin (Pharsight Co., Mountain View, CA). Within-time-point data were within $10 \%$ of the mean. Pharmacokinetic parameters including the total primaquine systemic exposure (AUC), elimination rate constant $(k)$, maximum plasma concentration $\left(C_{\max }\right)$, time for $C_{\max }\left(T_{\max }\right)$ and half-life values of primaquine were determined.

\section{Results}

Two sets of 21 mice were dosed with SPQ and RPQ, respectively, with each mouse receiving $45 \mathrm{mg} / \mathrm{kg}$ of $\mathrm{PQ}$ base. The average body weight of the mice was $34 \mathrm{~g}$ while the average PQ dose was $1.53 \mathrm{mg} / \mathrm{mouse}$. Tissue samples (plasma, liver, spleen, lungs, kidneys, and brain) were collected, and primaquine/metabolite concentrations were monitored and profiled against time.

\section{$\mathrm{PQ}$ enantiomer pharmacokinetics and tissue distribution $P Q$ enantiomer plasma pharmacokinetics}

The basic pharmacokinetic parameters for the two enantiomers are presented in Table 1 show more rapid plasma clearance for RPQ compared to SPQ, with no RPQ detected after $2 \mathrm{~h}$, compared to $8 \mathrm{~h}$ for SPQ. Plasma $C_{\max }$ is moderately lower for $\mathrm{RPQ}$, but the $T_{1 / 2}$ and $\mathrm{AUC}_{0 \text {-last }}$ are much lower. Peak plasma concentration is achieved more quickly, with $T_{\max }$ at 30 min or earlier. As suggested

Table 1 The plasma pharmacokinetic parameters of SPQ and $\mathrm{RPQ}$ in mice

\begin{tabular}{lll}
\hline & SPQ & RPQ \\
\hline Lag time $(\mathrm{h})$ & 0 & 0 \\
$C_{\text {max }}(\mu \mathrm{g} / \mathrm{mL})$ & $1.05 \pm 0.15$ & $0.72 \pm 0.11$ \\
$T_{\text {max }}(\mathrm{h})$ & 1 & 0.5 \\
$T_{\text {last }}(\mathrm{h})$ & 8 & 2 \\
$\mathrm{AUC}$ & 1.58 & 0.64 \\
$T_{1 / 2}(\mathrm{~h})$ & 1.9 & 0.45 \\
\hline
\end{tabular}

$C_{\max }$ maximum plasma concentration, $T_{\max }$ time for $C_{\max } T_{\text {last }}$ time for last measurable plasma concentration, $A U C$ area under the plasma concentrationtime curve, $T_{1 / 2}$ half-life 
by the liver concentration-time profile (Fig. 1), it appears that the difference in the $T_{\max }$ of the individual PQ enantiomers may be due to differential tissues perfusion rates, especially from the liver to the blood after the initial hepatic concentration.

\section{$P Q$ enantiomers tissue distribution}

Primaquine is preferentially concentrated in the liver compared to plasma and most other organs (Fig. 1), especially with SPQ. The concentrations of the SPQ enantiomer were higher than RPQ in the liver tissues at all the time points. At $T_{\max }$, the concentration of SPQ in liver is about 3 times that of RPQ; $(115 \mathrm{vs} .40 \mathrm{mg} / \mathrm{mL})$. At this point, the liver alone accounts for $20 \%$ of administered SPQ. Since the first sampling point of $30 \mathrm{~min}$ also happened to be the $T_{\max }$, the actual $T_{\max }$ for RPQ might be earlier than $30 \mathrm{~min}$. This suggests a rapid absorption and distribution of PQ enantiomers to the liver. At the $T_{\max }$, measured $\mathrm{C}_{\max }$ of SPQ and RPQ in the liver was about 100 and 40 times the value in the plasma respectively. In the other organs, the concentration of the SPQ enantiomer is also preferentially higher than in plasma. For example, at $T_{\max }$, the concentration of SPQ is about 5

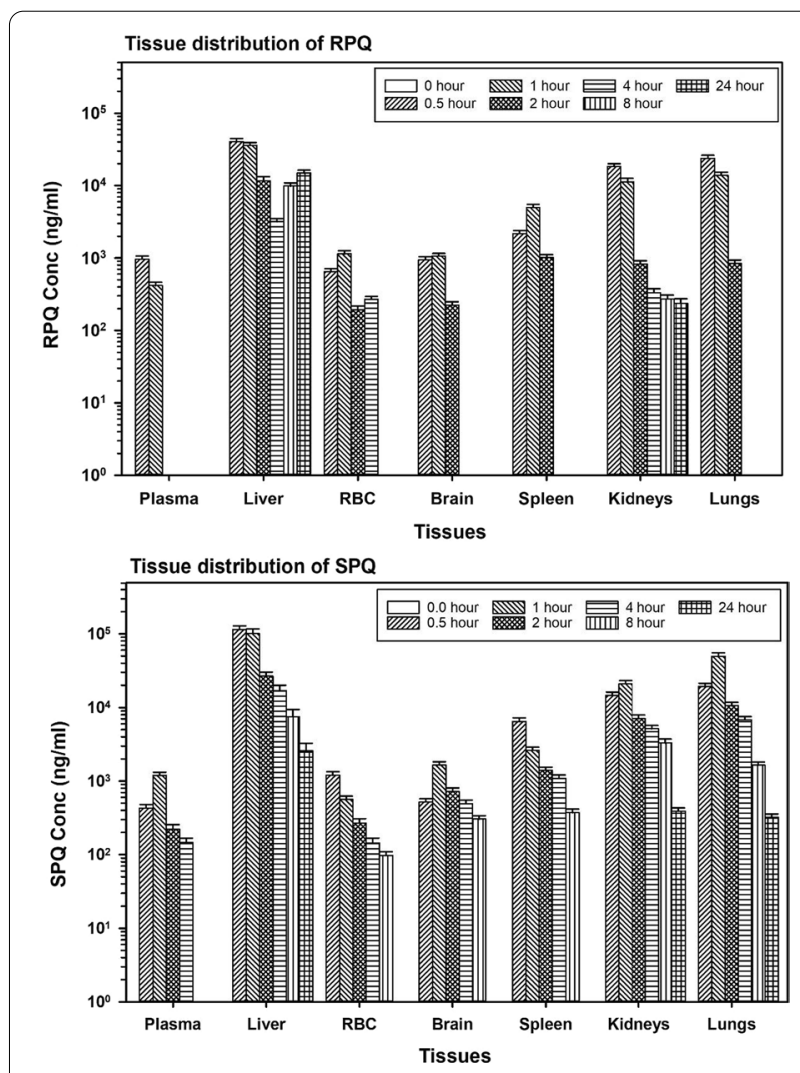

Fig. 1 Distribution and time course of primaquine enantiomers in mouse tissues. Data are the average of 3 mice per time point and are presented as mean \pm SEM times higher in the spleen and lungs, and about twice as high in the brain and kidneys, compared to plasma.

There is a notable difference in the time course of the liver profiles of RPQ and SPQ, with a biphasic increase in liver content of RPQ. The second peak of hepatic RPQ occurs between the 4-h and 8-h time points and increases further at $24 \mathrm{~h}$. This biphasic pattern for tissue distribution is absent with SPQ.

\section{Major metabolites \\ Plasma and tissue concentrations of carboxyprimaquine}

Carboxyprimaquine (cPQ), the primary metabolite of primaquine, was the most abundant metabolite formed and was found in plasma and all the tissues. These results are shown in Figs. 2 and 3. Figure 2 compares the relative time-course for formation of $\mathrm{cPQ}$ from individual PQ enantiomers, and their comparative profiles in plasma and liver. As expected, based on previous studies, RPQ consistently generated more $\mathrm{CPQ}$ as compared SPQ. CPQ was a major metabolite in plasma, with significant amounts found in the liver. The concentrations of $\mathrm{CPQ}$ are higher in plasma than in liver, especially for $R P Q$, even though the parent PQ content of both enantiomers is much higher in liver than in plasma.

The formation of $c P Q$ is faster with $R P Q$, peaking at $30 \mathrm{~min}$ in both plasma and liver (first time-point) compared to $1 \mathrm{~h}$ with SPQ. At Tmax, the level of cPQ from RPQ in liver is about $10 \times$ greater than the level formed from SPQ. CPQ is about 3.5-fold higher in the plasma after RPQ administration, as compared to SPQ. The biphasic pattern observed with RPQ in liver (Fig. 1) is mirrored in the biphasic appearance of $\mathrm{CPQ}$ in plasma from $R P Q$, but this is absent or minimal with SPQ.

Carboxyprimaquine (cPQ) was found in all the organs except in the spleen (Fig. 3). Except for plasma, cPQ is much lower in the tissues compared to the parent RPQ or SPQ. In plasma, for both enantiomers, the concentration of $\mathrm{CPQ}$ far exceeds that of $\mathrm{PQ}$ at the $\mathrm{T}_{\max }$.

\section{Primaquine 5,6-o-quinone}

Primaquine 5,6-o-quinone is a stable surrogate of the reactive, unstable 5-hydroxyprimaquine metabolite. Figures 4 and 5 compare the kinetics of primaquine $o$-quinone generated from individual PQ enantiomers. $O$-quinone was primarily formed in the liver, with about 4 times more from SPQ than from RPQ. The $o$-quinone was also observed at appreciable concentrations in RBCs. In plasma, only trace amounts of $o$-quinone were detected from RPQ, and none from SPQ. The concentration of $o$-quinone formed from SPQ in RBC is about twofold higher than formed from RPQ at the $\mathrm{T}_{\max }$, thus mirroring the plasma PQ profiles, rather than the plasma $o$-quinone profiles. 

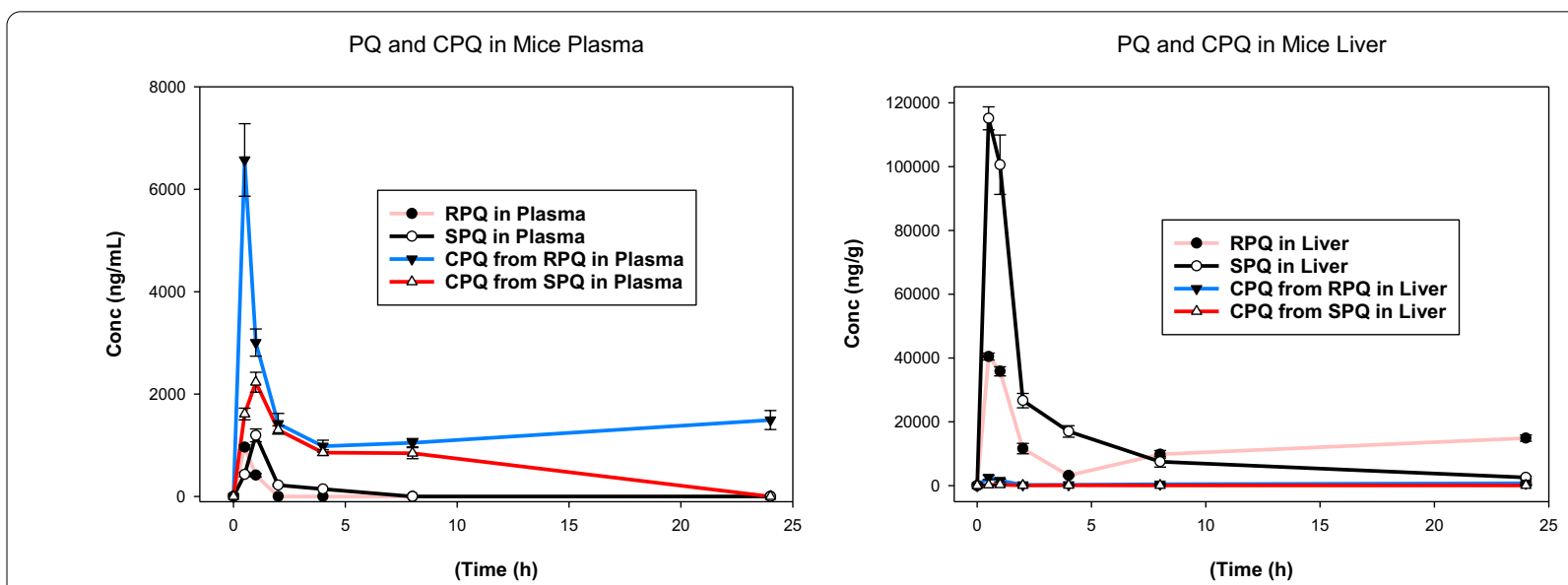

Fig. 2 Time course of concentrations of primaquine and carboxyprimaquine in plasma and liver after RPQ and SPQ administration. Data shown are mean $\pm \operatorname{SEM}(n=3)$ in mouse plasma (left panel) and liver (right panel)

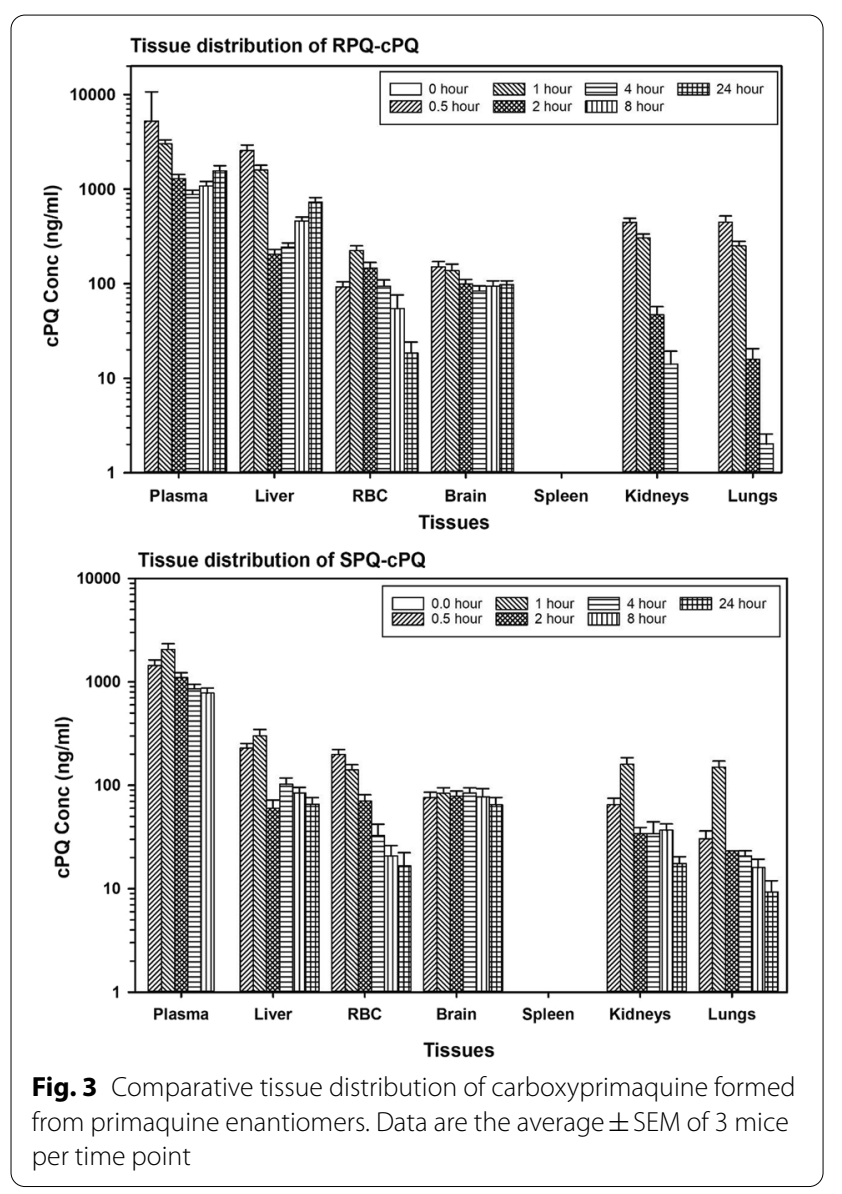

\section{Other plasma and tissue metabolites}

A number of other PQ metabolites were identified in plasma and tissues. The identity of these metabolites was established with the MetaboLynx ${ }^{\mathrm{TM}}$ XS application manager (Waters USA) based on retention time, accurate mass and high-resolution mass fragmentation pattern with twin stable isotope peaks [40]. The summary of these metabolites (with their putative identity) is provided in Table 2. Secondary metabolites (Phase II metabolism) found in this mouse tissue study include the $\mathrm{N}$-glucuronide of primaquine $(\mathrm{m} / \mathrm{z} 436)$ and phenolic glucuronides of two hydroxy-primaquines $(\mathrm{m} / \mathrm{z} 452)$, along with a glycosylated primaquine derivative $(\mathrm{m} / \mathrm{z} 422)$.

An apparent glucuronide of primaquine $(\mathrm{m} / \mathrm{z} 436, \mathrm{RT}$ $2.17 \mathrm{~min}$ ) was found in the plasma only, with no remarkable differences in the enantiomers. Hydroxy-primaquine glucuronides $(\mathrm{m} / \mathrm{z} 452)$ were also major secondary metabolites of PQ found in this study. Two different glucuronides (distinguished by their retention times 1.9 and $9.26 \mathrm{~min}$ ), likely formed from the glucuronidation of two of 2-, 3-, 4- or 5-hydroxyprimaquines, were detected. The first hydroxy-primaquine glucuronide (RT $1.9 \mathrm{~min}$ ) was found only in the plasma and was exclusively formed from the SPQ enantiomer. The second glucuronide (RT $9.26 \mathrm{~min}$ ) had a wider distribution across the tissues (liver, RBC, kidneys, and lungs), and was formed from both enantiomers.

A glycosylated PQ (RT 4.9 min) was more abundantly formed in the liver than in the plasma; but was relatively more abundantly generated from SPQ in the liver and from RPQ in the plasma. Other metabolites detected include an apparent acetylated dihydroxy-primaquine quinone-imine $(\mathrm{m} / \mathrm{z} 332)$ which was formed only from $\mathrm{RPQ}$ and found only in the plasma and liver; primaquine$\mathrm{N}$-carbamoyl-glucuronide conjugate $(\mathrm{m} / \mathrm{z} \quad 480)$ was found only in the plasma and formed from both enantiomers; and there were traces of a PQ quinone-imine $(\mathrm{m} / \mathrm{z} 274)$, presumably derived from $5-\mathrm{OH}-\mathrm{PQ}-$ and an 


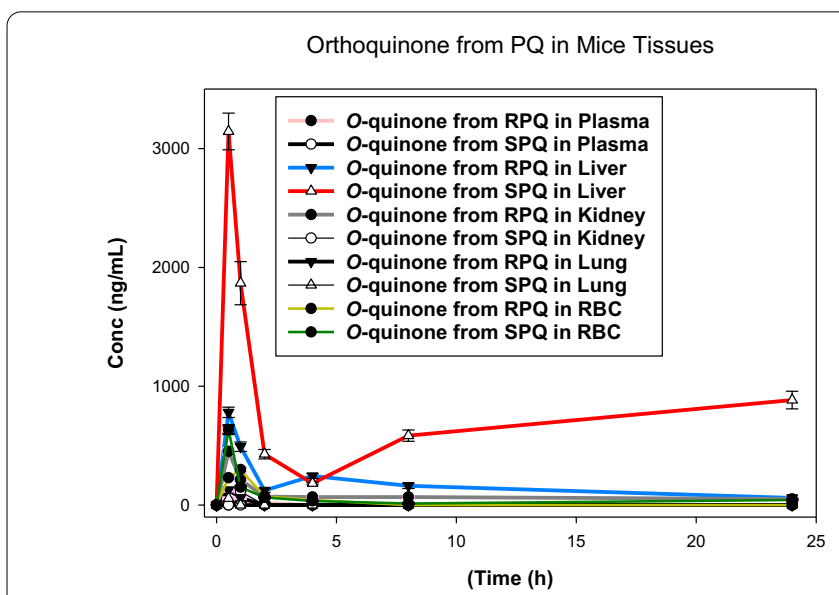

Orthoquinone from $\mathrm{PQ}$ in Mice Tissues (minus liver)

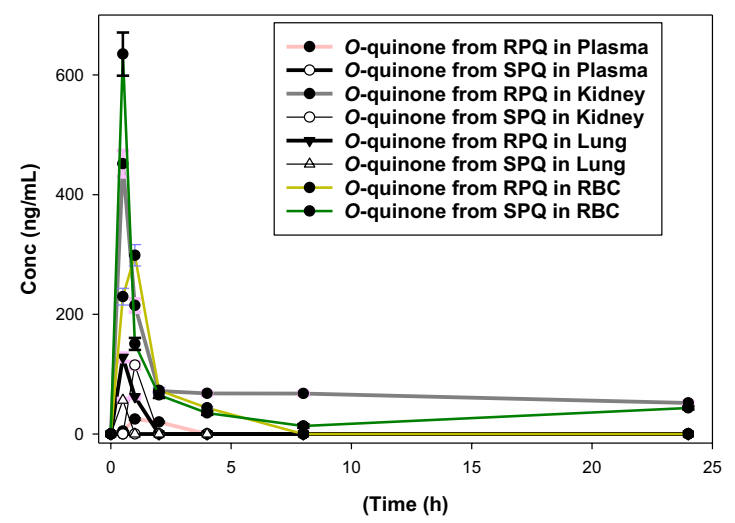

Fig. 4 Time course of concentrations of $P Q-5,6-o-q u i n o n e$ after administration of individual RPQ and SPQ. Data shown are mean $\pm S E M(n=3)$ in mouse plasma, liver (left panel) or plasma and erythrocytes (right panel)

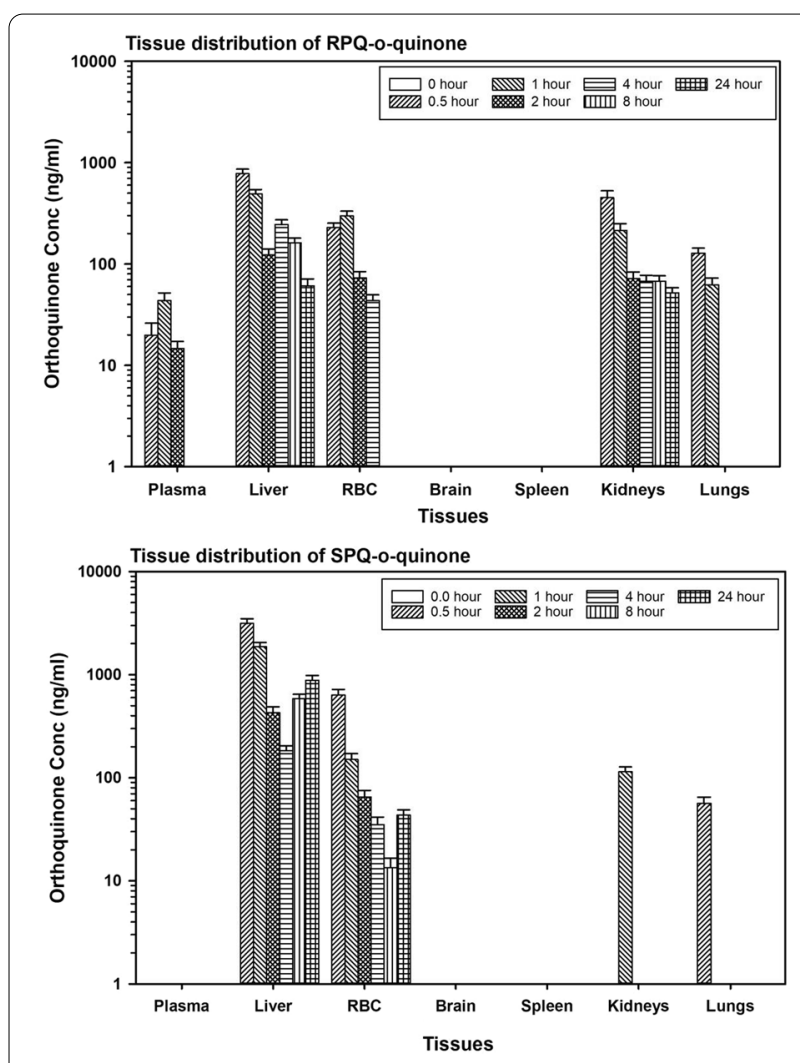

Fig. 5 Time course of concentrations of PQ-o-quinone after RPQ and SPQ administration. Data are the average \pm SEM of 3 mice per time point

intermediate leading to the PQ-o-quinone-formed from both enantiomers and found only in the plasma.

\section{Urine metabolites}

Several of these metabolites, along with additional ones, were recovered from the mouse urine. Table 3 shows the relative presence of the identified metabolites from the two PQ enantiomers. Shaded rows indicate the metabolites also seen in plasma or tissues.

\section{Discussion}

This study presents a comprehensive pharmacokinetic and tissue bio-distribution analysis of PQ and key metabolites in healthy mice administered a single dose of the individual PQ enantiomers. It is well established that for chiral drugs, pharmacological and toxicological effects of the enantiomers may vary substantially; this divergence may be due to pharmacodynamic considerations (e.g., target receptor interactions) but may also be dependent on differential absorption, distribution, metabolism, and excretion profiles [43]. This phenomenon has been shown to be of critical importance for several drugs and antimalarial drug-drug interactions $[41,44]$.

For $\mathrm{PQ}$, evidences from a number of in vitro $[28,29]$ and in vivo [31, 44] studies have established that the metabolism to $\mathrm{CPQ}$, which is a major metabolic route, is distinctly stereoselective, with RPQ giving rise to more of the CPQ metabolite, likely because it is a better substrate for monoamine oxidases than SPQ [30]. Differences in in vivo pharmacodynamic and toxicological profiles with the PQ enantiomers have been observed in other studies in mice, dogs [34] and primates [35, 36].

Based on in vitro studies with individual PQ enantiomers, it was established that besides metabolism of $\mathrm{PQ}$ to $\mathrm{CPQ}$, other important PQ metabolic pathways also show potential stereoselectivity with regard to the PQ enantiomers. The SPQ enantiomer, more than the 
Table 2 Other metabolites formed by PQ enantiomers as observed in different mouse tissues

\begin{tabular}{|c|c|c|c|}
\hline Mass $(M+1)$ & $\begin{array}{l}\text { Retention } \\
\text { time (min) }\end{array}$ & Putative identity & Key findings \\
\hline 274.1544 & 2.35 & Hydroxylation and quinone-imine formation & Formed from both enantiomers, found only in the plasma \\
\hline 332.1604 & 7.7 & Acetylated dihydroxy-PQ quinone-imine & Formed from RPQ and found in plasma and liver \\
\hline 422.1929 & 4.9 & Glycosylated primaquine & Higher amount formed from SPQ than RPQ; found in the plasma and liver \\
\hline 436.1992 & 2.17 & Primaquine glucuronide & $\begin{array}{l}\text { Present only in the plasma with no remarkable enantiomeric difference in } \\
\text { the profiles }\end{array}$ \\
\hline 452.2027 & 1.9 & Hydroxy-primaquine glucuronide & Formed only from the SPQ enantiomer and found only in the in the plasma \\
\hline 452.2027 & 9.26 & Hydroxy-primaquine glucuronide & $\begin{array}{l}\text { Formed from both enantiomers and found in the liver, RBC, kidneys and } \\
\text { lungs. No remarkable enantioselectivity }\end{array}$ \\
\hline 480.1989 & 7.9 & Primaquine- $N$-carbamoyl glucuronide & Formed from both enantiomers; found only in the plasma \\
\hline
\end{tabular}

Table 3 Urinary metabolites (and their putative identities) detected in mice following the administration of RPQ and SPQ

\begin{tabular}{|c|c|c|c|c|}
\hline \multirow[t]{2}{*}{ Mass $(M+1)$} & \multirow[t]{2}{*}{ Retention time (min) } & \multirow[t]{2}{*}{ Description } & \multicolumn{2}{|c|}{ Relative presence } \\
\hline & & & $\mathrm{RPQ}$ & SPQ \\
\hline 246.1585 & 4.3 & Demethylated primaquine & + & + \\
\hline 260.1408 & 1.87 & Primaquine-o-quinone & + & + \\
\hline 261.1609 & 8.7 & Oxidative deamination to primaquine alcohol & ++ & + \\
\hline 274.1544 & 2.35 & Hydroxylation and quinone-imine formation & + & - \\
\hline 276.1690 & 4.18 & 2-Hydroxy-primaquine & - & + \\
\hline 276.1691 & 4.88 & 3-Hydroxy-primaquine & + & - \\
\hline 289.1531 & 10.04 & CarboxyPQ o-quinone & + & - \\
\hline 290.1510 & 3.45 & Dihydroxy-PQ quinone imine & + & - \\
\hline 332.1604 & 7.7 & Acetylated dihydroxy-PQ quinone-imine & ++ & + \\
\hline 422.1929 & 2.3 & Demethylation + glucuronidation & + & + \\
\hline 422.2266 & 4.9 & Glycosylated primaquine & + & + \\
\hline 452.2027 & 1.9 & Hydroxy-primaquine glucuronide & - & + \\
\hline 452.2027 & 2.37 & Hydroxy-primaquine glucuronide & + & - \\
\hline 452.2027 & 3.4 & Hydroxy-primaquine glucuronide & + & + \\
\hline 452.2027 & 4.3 & Hydroxy-primaquine glucuronide & - & + \\
\hline 467.1642 & 5.6 & Glucuronide of hydroxylated carboxyprimaquine & - & + \\
\hline 467.1642 & 7.27 & Glucuronide of hydroxylated carboxyprimaquine & + & - \\
\hline 480.1989 & 7.9 & Primaquine- $\mathrm{N}$-carbamoyl glucuronide & + & + \\
\hline 494.2125 & 3.0 & Primaquine acetylation, hydroxylation and glucuronidation & + & - \\
\hline 494.2125 & 2.9 & Primaquine acetylation, hydroxylation and glucuronidation & - & + \\
\hline 494.2125 & 4.7 & Primaquine acetylation, hydroxylation and glucuronidation & - & + \\
\hline
\end{tabular}

$(-)$ denotes the absence of the metabolite. Where present in both enantiomers, relative amount is denoted with $(+)$ and $(++)$ denoting low and high amounts respectively

$R P Q$, is susceptible to the quinoline ring oxidation via CYP-dependent metabolism [30]. This finding points toward the likelihood that SPQ may display greater antimalarial (radical curative) potency than RPQ. However, organ-specific uptake of parent drug and production of the metabolites will also be important considerations for understanding of the pharmacodynamics of PQ, along with the distribution and further metabolism of metabolites.

It is of interest that the half-life of both enantiomers in tissues appears to be much longer than the half-life in plasma, reflecting the known high volume of distribution of this drug [45]. This is consistent with a slow back equilibration of the drug from tissue binding sites before elimination in the liver. However, and most noticeable 
for the $\mathrm{R}$ enantiomer relative to the $\mathrm{S}$ analog, the concentrations in the liver at long time intervals are much greater than in other 'binding' tissues with the possible exception of the kidney. This implies the presence of non-metabolism related binding sites in the liver. The data from current study also suggests that the elimination of the SPQ from the liver is faster and more consistent with its plasma half-life, as compared with that of the RPQ, again implying something special about the $R$ isomer's non-metabolic binding in the liver. Of interest, SPQ has been reported to show a higher activity against sporozoite-induced liver stage malaria infections in mice [34]. Whether this is due to relative sequestration of the $\mathrm{R}$ isomer and hence lower metabolic activation to the active species is not yet clear, but it raises the possibility that preservation of the $\mathrm{R}$ species in the liver may be relevant to activity of $\mathrm{PQ}$ towards mature and infective gametocytes, whether with or without further activation. In addition, whether any such 'activated metabolites' differ from those that elicit radical cure of $P$. vivax. The extended high levels relative to plasma in the lungs are notable, especially for the SPQ enantiomer. Further studies in this regard may explore potential activity of PQ or other 8-aminoquinolines against pulmonary parasite infections. PQ-based combinations have shown utility for treatment of Pneumocystis jirovecii (carinii) pneumonia causing lung cystic lesions [46, 47].

Collectively, the tissue distribution data showing sustained concentrations of both isomers, relative to plasma levels, emphasize that the biological half-life of the drug, towards both the therapeutic and toxic endpoints, is likely to be much greater than that predicted by plasma half-life alone, and may further differ depending on the endpoint, hepatic sporozoites or circulating gametocytes eradication.

Formation of cPQ showed significant enantioselectivity with markedly higher levels of R-cPQ (Fig. 2). As expected from its much smaller Vd compared to that that of PQ $[29,45]$, it was more concentrated in the plasma than in the tissues. Of note, the concentrations of $\mathrm{CPQ}$ for both isomers in plasma and other tissues were maintained for up to $24 \mathrm{~h}$, again raising the issue of the potential role of $\mathrm{CPQ}$ in the therapeutic and toxicological responses to PQ in experimental animals and patients [32]. Identification of carboxyPQ $o$-quinone in the urine indicates that ring oxidation of $\mathrm{CPQ}$ occurs in vivo and could contribute to the biological activities of PQ. Whether this pathway is quantitatively important for therapeutic/toxicological effects remains to be determined.

As illustrated in Fig. 2, R-cPQ appears to show a biphasic response, an initial rapid decrease, presumably reflecting both metabolic clearance and tissue distribution, followed by an increase starting at about the $2 \mathrm{~h}$ time point. The mechanism underlying this increase and persistence is unclear; an enterohepatic circulation of a cPQ metabolite such as the acyl-glucuronide is conceivable especially because the presence of gall bladder in mice favors intermittent dumping of bile followed by reabsorption. In view of the marked difference in the initial clearance of RPQ vs SPQ, it seems reasonable that if the $c P Q$ metabolite plays a role in the formation of the ultimate active/toxic metabolites, its contribution would be most marked for the $\mathrm{R}$ isomer. This study provides extended results on low tissue distribution of $\mathrm{CPQ}$ and supplement earlier clinical studies on differential PK profiles of $\mathrm{cPQ}$ enantiomers [31].

Primaquine 5,6-o-quinone, potentially generated through CYP2D6 meditated pathway has been implicated in the therapeutic/toxic actions of PQ [30, 48, 49]. In this study, low concentrations of $o$-quinone of the $\mathrm{R}$ isomer were detected in plasma, but none from the $\mathrm{S}$ isomer (Fig. 5). The o-quinone from both isomers was present in significant concentration in the liver, and to smaller extent, in the kidney and lungs. Earlier clinical studies have also failed to detect primaquine-o-quinone in plasma of healthy human volunteers treated with PQ single dose $[32,50]$, possibly reflecting rapid uptake into RBCs or distribution to tissues. As shown in Fig. 5, in spite of low plasma concentrations, the $o$-quinone was present in substantial amounts (hundreds of $\mathrm{ng} / \mathrm{ml}$ ) in RBCs. There was persistent presence of this potentially haemotoxic species in both the RBCs and liver long after the elimination of the parent compounds. The origin of $o$-quinone in the RBC is of interest. The capacity of oxyhaemoglobin to mediate the oxidation of drugs is long known, albeit sluggish as compared to the hepatic P450 system. With regard to $\mathrm{PQ}$, it has been shown that the $o$-quinone can be produced from PQ in an in vitro incubation with RBC [51]. The contribution of RBC in situ oxidation vs hepatic P450 formation/transport to the $\mathrm{RBC}$ remains to be determined.

Enantioselectivity in metabolic clearance of drugs is well known. The enantioselectivity of PQ metabolism is prominent: the long recognized major difference in rate of MAO-induced formation of $\mathrm{CPQ}$ for the two enantiomers can be extended to other pathways. The $c P Q$ formation from RPQ results in two species (parent and metabolite) with markedly different tissue distribution and persistence; both have the metabolic potential for activation(s) needed for the therapeutic and haemotoxicity of the parent compound. The hydroxylated metabolites, including PQ-o-quinone (presumably CYPdependent), is observed with both enantiomers; however, the specific metabolites formed and tissue distribution varies between the two enantiomers. Other metabolites with notable enantioselectivity include the glucosyl PQ 
and hydroxyPQ glucuronide, both of which were preferentially generated from the SPQ. A large number of metabolites were found in the mouse urine with a number of them showing enantioselectivity. Many of these metabolites have been earlier detected in urine in a clinical study [32].

The $o$-quinone in liver tissue also reflects a biphasic profile, especially with the SPQ; this suggests some recycling of this or other (upstream) metabolites. This may be attributed to the difficulty of isolating the unstable intermediates 5-hydroxy-PQ, PQ-quinone-imine, and 5,6-dihydroxy-PQ. If one or more of these has an affinity for the tissues that stabilizes them or delays their release and breakdown to the $o$-quinone, this may also account for this puzzling finding.

The presence of $o$-quinone in the RBCs is remarkable. While it is not clear whether the $o$-quinone produced in the liver is transported to the $\mathrm{RBC}$, an earlier study has shown that $o$-quinone can be produced via direct oxidation of PQ on in vitro incubation with RBCs [51]. The $\mathrm{RBC}$ concentration of $o$-quinone however, raises questions regarding its role in the haemotoxicity associated with PQ, and/or the gametocytocidal activity of PQ [10]. A recent report has suggested the role of CYP mediated pathway in gametocytocidal activity but not with treatment safety [52].

This study has further highlighted the potential role of tissue distribution in PQ activity/toxicity, and why this role may not be the same for both enantiomers. Together with earlier findings, the current study suggests that PQ enantiomers may be regarded as two different drugs with remarkable differences in pharmacokinetics, metabolism, and tissue distribution, which translate into different efficacy and safety profiles of individual enantiomers. Ongoing clinical studies with individual PQ enantiomers in normal and G6PD deficient individuals $[38,53]$ will further inform the applicability of these current findings.

\section{Conclusion}

PQ enantiomers are differentially biodistributed and metabolized in mice, suggesting potential variation in the pharmacologic and toxicity profiles. Both enantiomers are extensively metabolized, but the specific metabolite patterns vary substantially. Systemic exposure to parent SPQ is far greater than observed with RPQ, and the conversion of RPQ to carboxy-primaquine is much higher than for SPQ. The findings are consistent with the higher activity of SPQ observed in the mouse causal prophylaxis test, and higher toxicity in the mouse model of haemolytic toxicity in G6PD deficiency [34]. The relevance of these findings to clinical use of racemic PQ and other 8-aminoquinolines vis-à-vis the actions of individual enantiomers remains to be explored in clinical studies. 


\section{Appendix 1: The distribution of primaquine in the different tissues of mice}
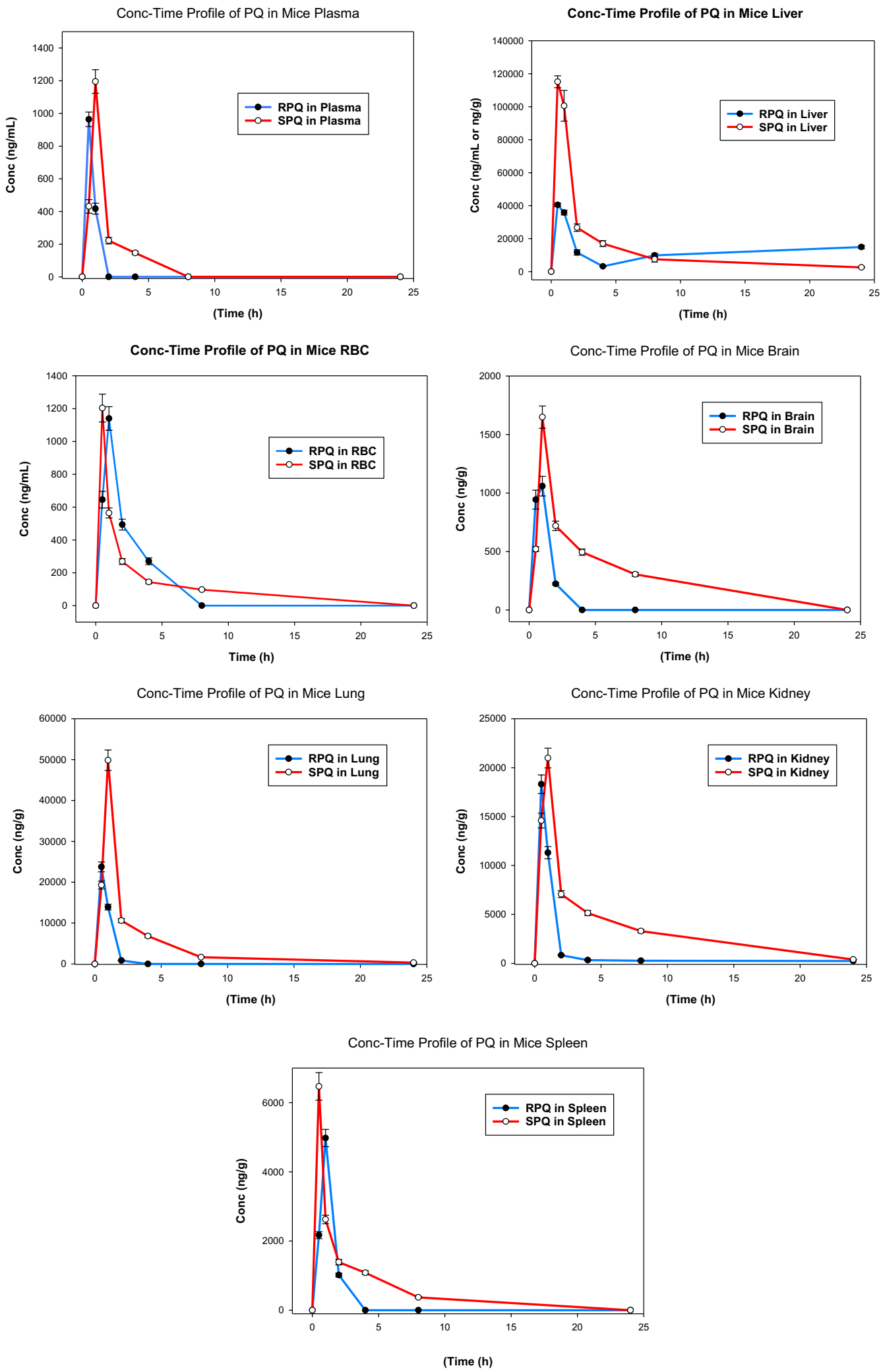


\section{Appendix 2: Time-tracked distribution} of carboxyprimaquine in mice tissues
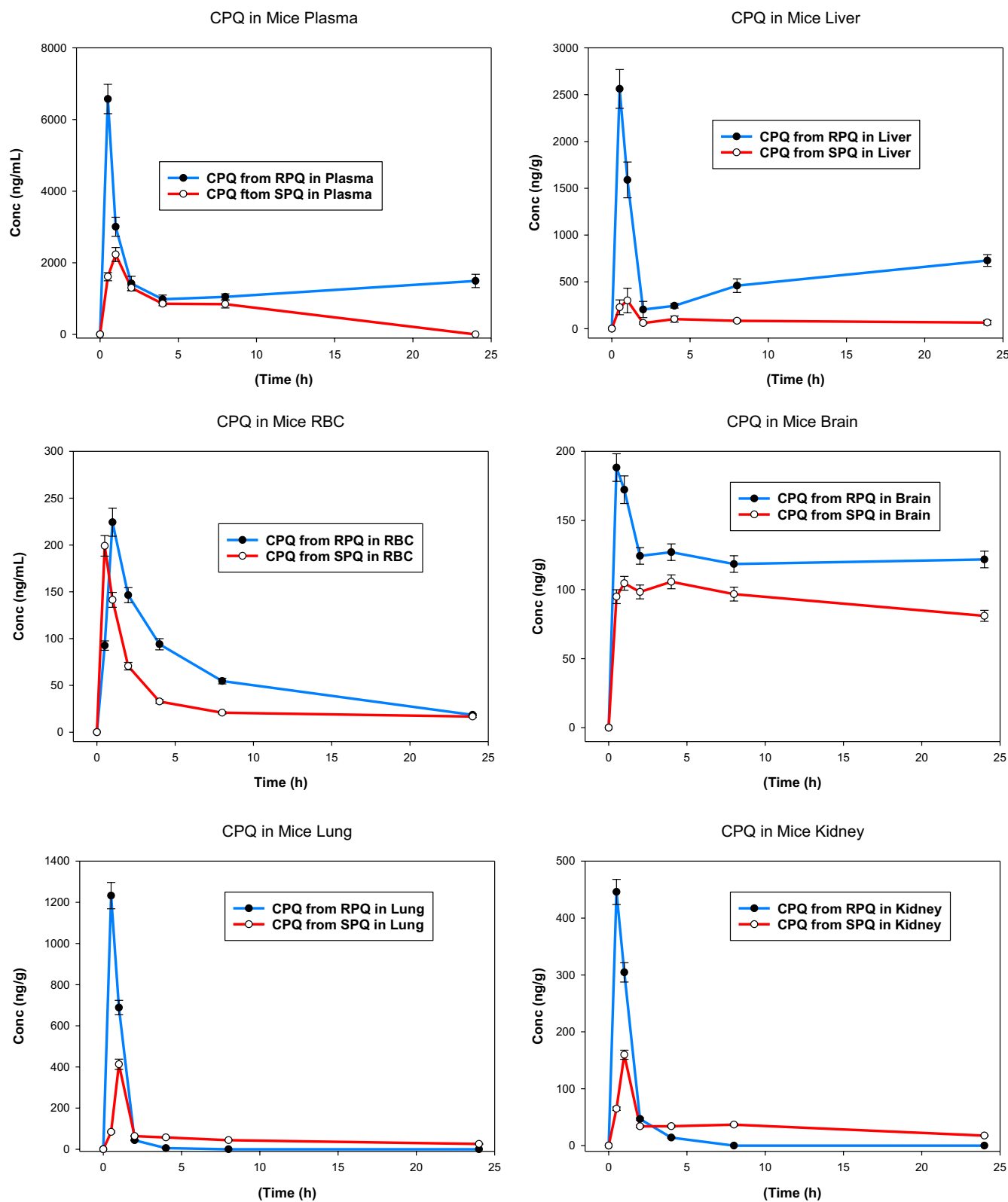

\section{Acknowledgements}

The authors are grateful for the support of the National Center for Natural Products Research, School of Pharmacy, University of Mississippi.

\section{Authors' contributions}

BLT and LAW conceptualized the study; BLT, LAW, PSF, and NDC designed the experimental procedures; PSF, NDC, NPDN, YHW, HMTBH, and BA conducted the dosing, sampling and chromatographic analysis. All authors contributed to the writing of the manuscript. All authors read and approved the final manuscript.

\section{Funding}

BT has been supported by an NIH-NIAID grant (1R01Al132579). This study was also supported by the US Army Medical Research and Materiel Command Awards No. W81XWH-13-2-0026. 


\section{Availability of data and materials}

All data generated or analysed during this study are included in this published article and its Additional files.

\section{Declarations}

\section{Ethics approval and consent to participate}

This study was conducted in compliance with the guidelines of the National Institutes of Health and the Animal Welfare Act. The research protocols were approved by the Institutional Animal Care and Use Committee of the University of Mississippi.

\section{Consent for publication}

Not applicable.

\section{Competing interests}

The authors declare that they have no competing interests.

\section{Author details}

${ }^{1}$ Department of Pharmacology \& Toxicology, University of Alabama at Birmingham, Birmingham, AL 35294, USA. ${ }^{2}$ Department of Infectious Diseases, Division of Scientific Platforms, Southern Research, Birmingham, AL 35205, USA. ${ }^{3}$ National Center for Natural Products Research, Research Institute of Pharmaceutical Sciences, School of Pharmacy, The University of Mississippi, University, MS 38677, USA. ${ }^{4}$ Cloaked Therapeutics, Inc., Etta, MS 38627, USA. ${ }^{5}$ Department of Pharmacology, Medical University of South Carolina, Charleston, SC, USA.

Received: 26 November 2021 Accepted: 18 January 2022 Published online: 05 February 2022

\section{References}

1. Thriemer K, Ley B, Bobogare A, Dysoley L, Alam MS, Pasaribu AP, et al. Challenges for achieving safe and effective radical cure of Plasmodium vivax: a round table discussion of the APMEN Vivax Working Group. Malar J. 2017;16:141.

2. Milligan R, Daher A, Graves PM. Primaquine at alternative dosing schedules for preventing relapse in people with Plasmodium vivax malaria. Cochrane Database Syst Rev. 2020;8:CD012656.

3. Price RN, Commons RJ, Battle KE, Thriemer K, Mendis K. Plasmodium vivax in the era of the shrinking P. falciparum map. Trends Parasitol. 2020;36:560-70.

4. Hossain MS, Commons RJ, Douglas NM, Thriemer K, Alemayehu BH, Amaratunga $C$, et al. The risk of Plasmodium vivax parasitaemia after $P$. falciparum malaria: an individual patient data meta-analysis from the WorldWide antimalarial resistance network. PLoS Med. 2020;17: e1003393.

5. Chu CS, White NJ. The prevention and treatment of Plasmodium vivax malaria. PLoS Med. 2021;18: e1003561.

6. Del-Tejo PL, Cubas-Vega N, Caraballo-Guerra C, da Silva BM, da Silva VJ, Sampaio VS, et al. Should we care about Plasmodium vivax and HIV co-infection? A systematic review and a cases series from the Brazilian Amazon. Malar J. 2021:20:13

7. White NJ. Primaquine to prevent transmission of falciparum malaria. Lancet Infect Dis. 2013;13:175-81.

8. Kondrashin A, Baranova AM, Ashley EA, Recht J, White NJ, Sergiev VP. Mass primaquine treatment to eliminate vivax malaria: lessons from the past. Malar J. 2014;13:51.

9. Graves PM, Choi L, Gelband H, Garner P. Primaquine or other 8-aminoquinolines for reducing Plasmodium falciparum transmission. Cochrane Database Syst Rev. 2018;2:CD008152.

10. Stepniewska K, Humphreys GS, Gonçalves BP, Craig E, Gosling R, Guerin $P J$, et al. Efficacy of single-dose primaquine with artemisinin combination therapy on Plasmodium falciparum gametocytes and transmission: an individual patient meta-analysis. J Infect Dis. 2020. https://doi.org/10. 1093/infdis/jiaa498.

11. Vantaux A, Kim S, Piv E, Chy S, Berne L, Khim N, et al. Significant efficacy of a single low dose of primaquine compared to stand-alone artemisinin combination therapy in reducing gametocyte carriage in Cambodian patients with uncomplicated multidrug-resistant Plasmodium falciparum malaria. Antimicrob Agents Chemother. 2020;64:e02108-19.

12. Von Seidlein L, Peto TJ, Landier J, Nguyen TN, Tripura R, Phommasone K, et al. The impact of targeted malaria elimination with mass drug administrations on falciparum malaria in Southeast Asia: a cluster randomised trial. PLOS Med. 2019;16: e1002745.

13. Taylor WR, Kim S, Kheng S, Muth S, Tor P, Christophel E, et al. Dynamics of G6PD activity in patients receiving weekly primaquine for therapy of Plasmodium vivax malaria. PLoS Negl Trop Dis. 2021;15: e0009690.

14. Sepúlveda N, Grignard L, Curry J, Mahey L, Bastiaens GJ, Tiono AB, et al. G6PD polymorphisms and hemolysis after antimalarial treatment with low single-dose primaquine: a pooled analysis of six African clinical trials. Front Genet. 2021;12: 645688.

15. Bancone G, Chu CS. G6PD variants and haemolytic sensitivity to primaquine and other drugs. Front Pharmacol. 2021;12: 638885.

16. Maier JD, Siegfried S, Gültekin N, Stanga Z, Baird JK, Grobusch MP, et al. Efficacy and safety of tafenoquine for malaria chemoprophylaxis (1998-2020): a systematic review and meta-analysis. Travel Med Infect Dis. 2021;39: 101908.

17. Rodrigo C, Rajapakse S, Fernando D. Tafenoquine for preventing relapse in people with Plasmodium vivax malaria. Cochrane Database Syst Rev. 2020;9:CD010458

18. Chu CS, Hwang J. Tafenoquine: a toxicity overview. Expert Opin Drug Saf. 2021;20:349-62.

19. Ganesan S, Chaurasiya ND, Sahu R, Walker LA, Tekwani BL. Understanding the mechanisms for metabolism-linked hemolytic toxicity of primaquine against glucose 6-phosphate dehydrogenase deficient human erythrocytes: evaluation of eryptotic pathway. Toxicology. 2012;294:54-60.

20. Baird JK, Louisa M, Noviyanti R, Ekawati L, Elyazar I, Subekti D, et al. Association of impaired cytochrome P450 2D6 activity genotype and phenotype with therapeutic efficacy of primaquine treatment for latent Plasmodium vivax malaria. JAMA Netw Open. 2018;1: e181449.

21. Silvino AC, Kano FS, Costa MA, Fontes CJ, Soares IS, de Brito CF, et al. Novel insights into Plasmodium vivax therapeutic failure: CYP2D6 activity and time of exposure to malaria modulate the risk of recurrence. Antimicrob Agents Chemother. 2020;64:e02056-19.

22. Jin X, Potter B, Luong TL, Nelson J, Vuong C, Potter C, et al. Pre-clinical evaluation of CYP 2D6 dependent drug-drug interactions between primaquine and SSRI/SNRI antidepressants. Malar J. 2016;15:280.

23. Marcsisin SR, Reichard G, Pybus BS. Primaquine pharmacology in the context of CYP 2D6 pharmacogenomics: current state of the art. Pharmacol Ther. 2016:161:1-10.

24. Pybus BS, Marcsisin SR, Jin X, Deye G, Sousa JC, Li Q, et al. The metabolism of primaquine to its active metabolite is dependent on CYP 2D6. Malar J. 2013;12:212.

25. Bennett JW, Pybus BS, Yadava A, Tosh D, Sousa JC, McCarthy WF, et al. Primaquine failure and cytochrome P-450 2D6 in Plasmodium vivax malaria. N Eng J Med. 2013;369:1381-2.

26. Potter BM, Xie LH, Vuong C, Zhang J, Zhang P, Duan D, et al. Differential CYP 2D6 metabolism alters primaquine pharmacokinetics. Antimicrob Agents Chemother. 2015;59:2380-7.

27. Fasinu PS, Tekwani BL, Avula B, Chaurasiya ND, Nanayakkara NP, Wang YH, et al. Pathway-specific inhibition of primaquine metabolism by chloroquine/quinine. Malar J. 2016;15:466.

28. Nicholl DD, Edwards G, Ward SA, Orme ML, Breckenridge AM. The disposition of primaquine in the isolated perfused rat liver. Stereoselective formation of the carboxylic acid metabolite. Biochem Pharmacol. 1987;36:3365-9.

29. Baker JK, McChesney JD. Differential metabolism of the enantiomers of primaquine. J Pharm Sci. 1988;77:380-2.

30. Fasinu PS, Tekwani BL, Nanayakkara NP, Avula B, Herath HM, Wang YH, et al. Enantioselective metabolism of primaquine by human CYP2D6. Malar J. 2014;13:507.

31. Tekwani BL, Avula B, Sahu R, Chaurasiya ND, Khan SI, Jain S, et al. Enantioselective pharmacokinetics of primaquine in healthy human volunteers. Drug Metab Dispos. 2015:43:571-7.

32. Avula B, Tekwani BL, Chaurasiya ND, Fasinu P, Nanayakkara ND, Herath HB, et al. Metabolism of primaquine in normal human volunteers: investigation of phase I and phase II metabolites from plasma and urine using ultra-high performance liquid chromatography-quadrupole time-offlight mass spectrometry. Malar J. 2018;17:294. 
33. Fasinu PS, Avula B, Tekwani BL, Nanayakkara NP, Wang YH, Herath HB, et al. Differential kinetic profiles and metabolism of primaquine enantiomers by human hepatocytes. Malar J. 2016;15:224.

34. Nanayakkara ND, Tekwani BL, Herath HB, Sahu R, Gettayacamin M, Tungtaeng A, et al. Scalable preparation and differential pharmacologic and toxicologic profiles of primaquine enantiomers. Antimicrob Agents Chemother. 2014;58:4737-44.

35. Saunders $D$, Vanachayangkul $P$, Imerbsin $R$, Khemawoot $P$, Siripokasupkul $\mathrm{R}$, Tekwani BL, et al. Pharmacokinetics and pharmacodynamics of (+)-primaquine and (-)-primaquine enantiomers in rhesus macaques (Macaca mulatta). Antimicrob Agents Chemother. 2014;58:7283-91.

36. Schmidt LH, Alexander S, Allen L, Rasco J. Comparison of the curative antimalarial activities and toxicities of primaquine and its $\mathrm{d}$ and $\mathrm{I}$ isomers. Antimicrob Agents Chemother. 1977;12:51-60.

37. Clinical trials - NCT03934450. Metabolism and pharmacokinetics of primaquine enantiomers in human volunteers receiving a seven day dose regimen. https://clinicaltrials.gov/ct2/show/NCT03934450?term=NCT03 $934450 \& d r a w=2 \& r a n k=1$. Accessed Oct 202021.

38. Clinical trials NCT02898779-metabolism and pharmacokinetics of primaquine enantiomers in human volunteers, study 1. https:/clinicaltrials. gov/ct2/show/NCT02898779?term =NCT02898779\&draw $=2 \&$ rank $=1$. Accessed Oct 202021.

39. Lehmann WD. A timeline of stable isotopes and mass spectrometry in the life sciences. Mass Spectrom Rev. 2017;36:58-85.

40. Avula B, Tekwani BL, Chaurasiya ND, Nanayakkara ND, Wang YH, Khan SI, et al. Profiling primaquine metabolites in primary human hepatocytes using UHPLC-QTOF-MS with 13C stable isotope labeling. J Mass Spectrom. 2013;48:276-85.

41. Brocks DR, Mehvar R. Stereoselectivity in the pharmacodynamics and pharmacokinetics of the chiral antimalarial drugs. Clin Pharmacokinet. 2003:42:1359-82.

42. Clark JD, Gebhart GF, Gonder JC, Keeling ME, Kohn DF. The 1996 guide for the care and use of laboratory animals. ILAR J. 1997;38:41-8.

43. Alkadi H, Jbeily R. Role of chirality in drugs: an overview. Infect Disord Drug Targets. 2018;18:88-95.

44. Chairat K, Jittamala P, Hanboonkunupakarn B, Pukrittayakamee S, Hanpithakpong W, Blessborn D, et al. Enantiospecific pharmacokinetics and drug-drug interactions of primaquine and blood-stage antimalarial drugs. J Antimicrob Chemother. 2018;73:3102-13.

45. Mihaly GW, Ward SA, Edwards G, Orme ML, Breckenridge AM. Pharmacokinetics of primaquine in man: identification of the carboxylic acid derivative as a major plasma metabolite. $\mathrm{Br} J$ Clin Pharmacol. $1984 ; 17: 441-6$.

46. Lei GS, Zhang C, Shao S, Jung HW, Durant PJ, Lee CH. All-trans retinoic acid in combination with primaquine clears pneumocystis infection. PLOS ONE. 2013;8: e53479.

47. Bukamur HS, Karem E, Fares S, Al-Ourani M, Al-Astal A. Pneumocystis jirovecii (carinii) pneumonia causing lung cystic lesions and pneumomediastinum in non-HIV infected patient. Respir Med Case Rep. 2018;25:174-6.

48. Pookmanee W, Thongthip S, Tankanitlert J, Mungthin M, Sukasem C, Wittayalertpanya S. Simplified and rapid determination of primaquine and 5, 6-orthoquinone primaquine by UHPLC-MS/MS: its application to a pharmacokinetic study. Molecules. 2021;26:4357.

49. Khan W, Wang YH, Nanayakkara ND, Herath HB, Catchings Z, Khan S, et al. Quantitative determination of primaquine-5, 6-ortho-quinone and carboxyprimaquine-5, 6-ortho-quinone in human erythrocytes by UHPLC-MS/MS. J Chromatogr B. 2021;1163: 122510.

50. Spring MD, Sousa JC, Li Q, Darko CA, Morrison MN, Marcsisin SR, et al. Determination of cytochrome P450 isoenzyme 2D6 (CYP2D6) genotypes and pharmacogenomic impact on primaquine metabolism in an activeduty US military population. J Infect Dis. 2019;220:1761-70.

51. Fasinu PS, Nanayakkara ND, Wang YH, Chaurasiya ND, Herath HB, McChesney JD, et al. Formation primaquine-5, 6-orthoquinone, the putative active and toxic metabolite of primaquine via direct oxidation in human erythrocytes. Malar J. 2019;18:30.

52. Pett H, Bradley J, Okebe J, Dicko A, Tiono AB, Gonçalves BP, et al. CYP2D6 polymorphisms and the safety and gametocytocidal activity of singledose primaquine for Plasmodium falciparum. Antimicrob Agents Chemother. 2019;63:e00538-19.
53. Clinical trial NCT04073953 — primaquine enantiomers in G6PD deficient human volunteers. https://clinicaltrials.gov/ct2/show/NCT04073953? term $=$ NCT04073953\&draw $=2 \&$ rank=1. Accessed Oct 202021.

\section{Publisher's Note}

Springer Nature remains neutral with regard to jurisdictional claims in published maps and institutional affiliations.
Ready to submit your research? Choose BMC and benefit from:

- fast, convenient online submission

- thorough peer review by experienced researchers in your field

- rapid publication on acceptance

- support for research data, including large and complex data types

- gold Open Access which fosters wider collaboration and increased citations

- maximum visibility for your research: over $100 \mathrm{M}$ website views per year

At BMC, research is always in progress.

Learn more biomedcentral.com/submissions 